\title{
Laparoskopik Adrenalektomi
}

Onur Kaygısız, Yakup Kordan, İsmet Yavaşcaoğlu

Bursa Uludağ Üniversitesi, Üroloji Anabilim Dalı, Bursa

Laparoskopik adrenalektomi ilk defa 1992 yılında Gagner ve arkadaşları tarafından tanımlanmış olup sonrasında benign adrenal kitlelerin cerrahisinde altın standart olarak klinik uygulamaya girmiştir (1). Yapılan karşılaştırmalı çalışmalarda minimal invaziv yaklaşımın açık cerrahiye göre morbidite, hastanede kalış süresi ve normal hayat aktivitesine dönüş süresi açısından avantajları olduğu gösterilmiştir $(2,3)$. Adrenal bez cerrahisinde laparoskopik adrenalektomi operasyonu transperitoneal veya retroperitoneal yolla yap1labilmektedir.

Transperitoneal yaklaşımın geniş ameliyat sahası sağlaması ve adrenal damarlara direk ulaşım gibi avantajları mevcuttur. Bu yaklaşımda intraperitoneal organlarda yaralanma riski daha fazladır. Retroperitoneal yolda ise intarabdominal organlarla ilişki olmaması avantaj sağlarken alanın dar olması, cerrahi sırasında yönlendirici anatomik alanların belirgin olmaması dezavantajlarını oluşturur. Obez hastalarda retroperitoneal yaklaşım transperitoneal yaklaşıma kıyasla avantajlıdır. Her iki yaklaşım morbidite,ameliyat süresi, hastanede kalış süresi ve normal hayat aktivitesine dönüş süresi açısından benzerdir (4). Laparoskopik adrenektomi ameliyatında deneyim 30 ila 40 vakada oluşmakta ve sonrasında da deneyimle cerrahi süre kısalmaktadır (5).

\section{Ön Hazırlık}

Adrenal kitleye laparoskopik müdahale planlamadan önce adrenal kitlenin fonksiyonel durumu hakkında bilgi sahibi olunmalıdır. Adrenal kitlenin fonksiyon durumuna göre ameliyat öncesinde, sırasında ve sonrasında medikal tedavi gerekebilir. Elektrolit ve metabolik anomaliler cerrahi öncesi düzeltilmelidir.

Feokrositoması olan hastaya tansiyon kontrolü için en az iki hafta öncesinde uzun etkili alfa blokör olan fenoksibenzamin başlanmalı, taşikardi olanlarda sonrasında $\beta$ blokör eklenmelidir. Anestezi sırasında da kan basıncı kontrolü sıkı şekilde yapılmalıdır. Ameliyat sonrası hipotansiyonu önlemek için sıvı yüklenmelidir (6).

Aldosteronoması olan hastalarda agresif olarak hipopotasemi düzeltilmelidir. Serum potasyumu 3,5 $\mathrm{mEq} / 1$ üzerinde tutulmalıdır, gerekirse spironolakton veya amilorid tedaviye eklenmelidir (6).

Cushing sendromu olan hastalarda ameliyat öncesi elektrolit anomalileri ve hiperglisemi düzeltilmelidir. Ayrıca ketokanazol, mitotan veya aminoglutehemid kullanılabilir. Bu hastalarda infeksiyona ve koagülasyona eğilim olduğu akılda tutulmalıdır (6). Bu hastalar tümör çıkarımı sonrası hidrokortizol tedavisi ile endokrin bölümüyle birlikte yakın işbirliğiyle takip edilmelidir.

Preoperatif tetkiklerde malignite şüphesi olan hastalarda yaklaşım farklılık gösterir. Malign kitlelerin tespitinde üç fazlı bilgisayarlı tomografi, kimyasal şift magnetik rezonans görüntüleme ve pozitron emisyon tomografi yardımcı olur (7). Adrenokortikal kanser olgularında, özellikle büyük kitlelerde, dokunun yumuşak ve frajil olması ve laparoskopi sırasında basınç altında çalışılmasına bağlı geliştiği düşünülen postoperatif erken dönemde sistemik metastazlar ve lokal nükslerin arttığını bildiren yayınların varlığı, bu vakalarda açık cerrahiyi tercih sebebi yapmaktadır (8-10). Bununla birlikte küçük kitlelerde benzer onkolojik sonuç bildiren çalışmalar da mevcuttur $(11,12)$. Bizim de henüz yayınlanmadığımiz serimizde adrenokortikal kanser olgularında cerrahi ve onkolojik prensiplere uyulmasına rağmen metastaz oranlarının laparoskopik cerrahide açı cerrahiye göre yüksek olduğu saptandi.

\section{Transperitoneal Teknik}

Cerrahi genel anestezi altında yapılır. Mide dekompresyonu için nazogastrik tüp yerleştirilir. Mesane drenajı için erkeklerde 16f, kadınlarda $14 \mathrm{~F}$ foley sonda kullanılır. Umblikus ameliyat masasının fleksiyon alanına gelecek şekilde hasta modifiye lateral dekubit pozisyonda hazırlanır. Tek taraflı adrenalektomilerde bu pozisyon barsakların aşağı hareketi sonrası geniş alan sağlamasıyla tercih edilirken bilateral olgularda anterior supin pozisyon tercih edilebilir. Saha temizliği ve örtünmeyi takiben cerrah hastanın karın tarafina, kamera portunu tutan birinci asistan cerrahin kaudaline, hemşire ve gerekirse ikinci asistan hastanın sırt tarafına geçer.

\section{a. Sol Transperitoneal Laparoskopik Adrenalektomi}

Kostal yayın iki parmak altından rektus kasının lateral sınırı ile birleştiği yerden cilt kesisini takiben veress iğnesi ile girilir. Veress iğnesi ile girilirken eksternal oblik ile transvers fasya ve peritonda iki direnç hissedilir, önce negatif basınç sonrasında sıvı verilerek peritona güvenle girildiğinden emin olduktan sonra $15 \mathrm{mmHg}$ basınçla pnömoperiton oluşturulur.

Midklavikular hat üzerinde kot kavsinin $2 \mathrm{~cm}$ kaudaline 


\section{LAPAROSKOPIK ADRENALEKTOMI}

$10 \mathrm{~mm}$ port yerleştirilir. Bu porttan konulan teleskop ile direk görüş altında 10mmlik ikinci port kot kavsinin $2 \mathrm{~cm}$ kaudalinde rektus kasının dış kenarına doğru, 5 veya $10 \mathrm{~mm}$ 'lik üçüncü port ise kot kavsinin $2 \mathrm{~cm}$ kaudalinde orta aksiller hatta yerleştirilir (Resim 1). Dalak ekartasyonuna gerek olursa 4 . Port hastanın vücut yapısına göre arka aksiller hatta uygun bir bölgeye yerleştirilir.

Todt çizgisi insize edildikten sonra inen kolon splenik fleksuradan sigmoide kadar mediale devrilerek retroperitona girilir. Bu serbestleme sırasında splenokolik ve splenorenal ligamanlar insize edilir (Resim 2a). Dalak diafram ve karın duvarı ile olan bağları diseke edilerek mediale mobilize edilir. Gerota fasyası kranialden insize edilmeye başlanarak renal vene ulaşılır. Ana adrenal venin renal vene döküldüğü bölge keskin ve künt diseksiyonla serbestlenir sonrasında adrenal ven cerrahi kliplerle kliplenerek kesilir (Resim 2b). Renal ven tarafına güvenlik amacıyla çift klip konmalıdır.

Adrenal venin klavuzluğunda adrenal bez medialde aortadan diseksiyonla ayrılır. Bu aşamada pankreas adrenal bez ile karışabileceğinden diseksiyon dikkatli yapılmalıdır. Doğru planda diseksiyon yapılıyorsa avasküler hatta kanama az olacaktır, eğer bu aşamada kanama artmış ise özellikle

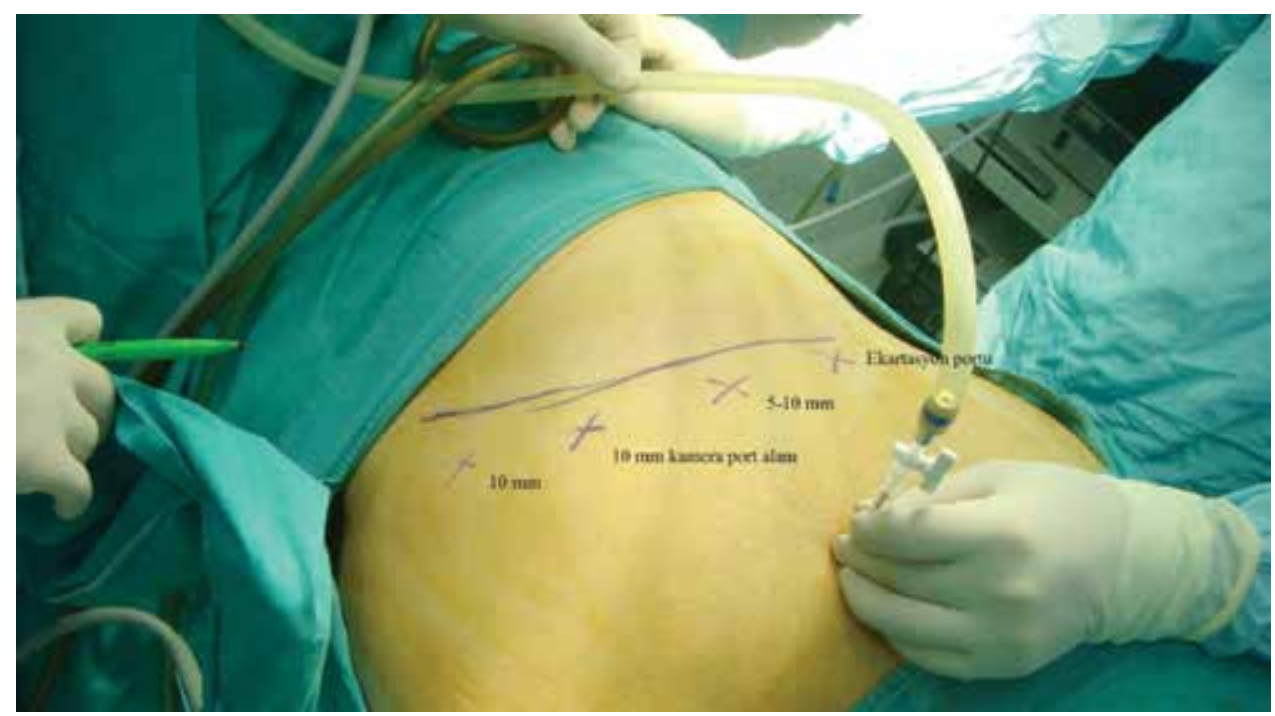

Resim 1: Sol laparoskopik adrenalektomi veress iğnesi ve port yerleşim düzeni

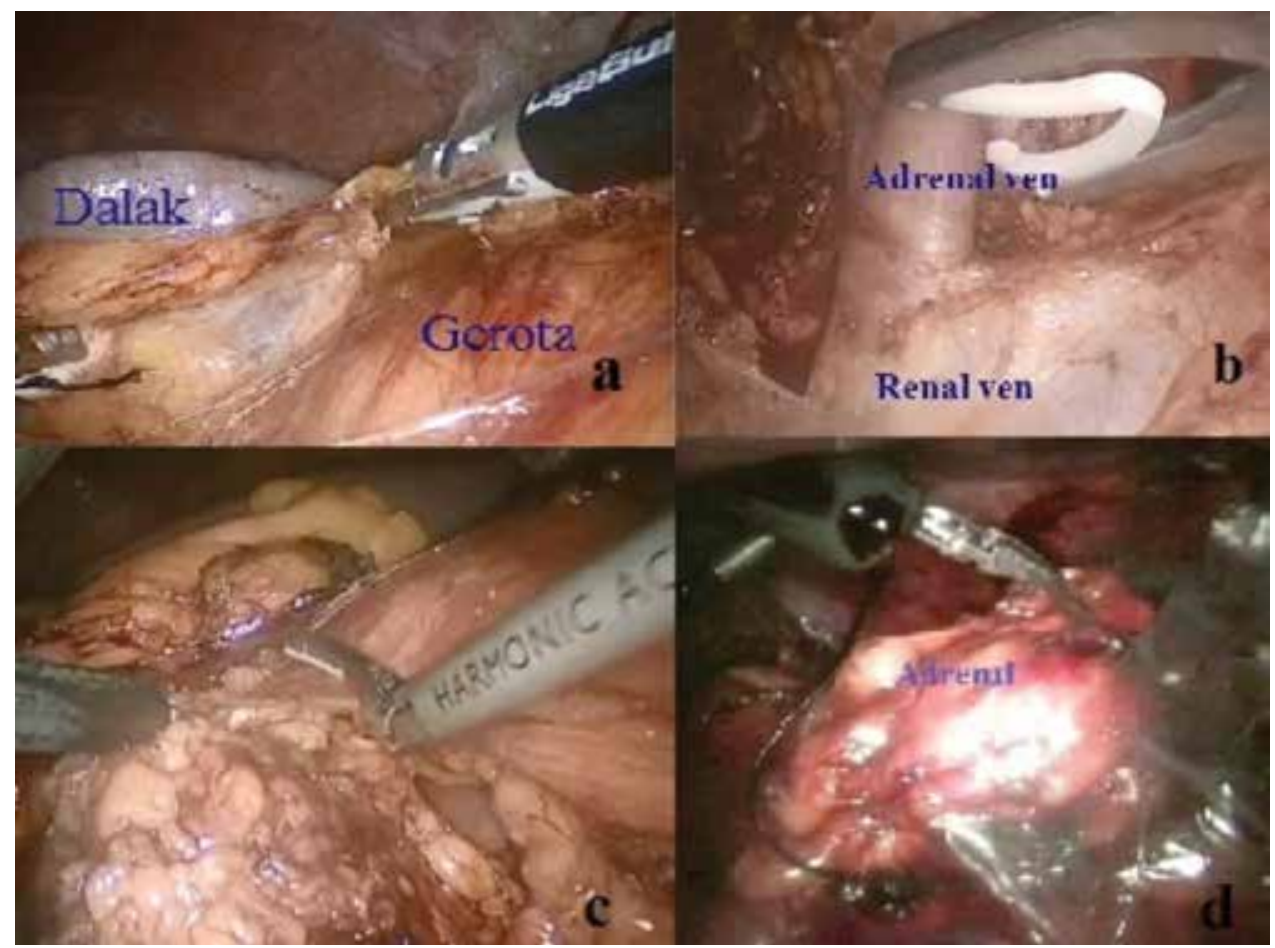

Resim 2: Laparoskopik sol adrenalektomi safhaları: a. Periton insizyonunu takiben dalak kaudalinde diseksiyon b. Sol adrenal venin kliplenmesi c. Sol adrenalin böbrekten diseksiyonu d.Eksize edilen adrenalin endobag'e yerleştirilmesi 
pankreas yaralanmasından korunmak için cerrahi plan tekrar gözden geçirilmelidir. Adrenal damarlar kliplenerek kesilir. Diseksiyon sırasında tam gözlenmeyen küçük damarların kanamasından kaçınmak için endoskopik mühürleme cihazları (ligasure veya ultracision) kullanılabilir. Sonrasında adrenal, böbrekten diseke edilerek işlem tamamlanır (Resim 2c). Doku endobag'e konularak ikinci port alanından dışarı alınır (Resim 2d). Pnömoperitonyum basınc $5 \mathrm{mmHg}$ düşürülerek kanama kontrolü yapılır ve işlem sonlandırılır. Ameliyattaki kanama veya komplikasyon durumuna göre loja dren konabilir.

\section{b. Sağ Transperitoneal Laparoskopik Adrenalektomi}

Sol taraf port dizilimine benzer şekilde sağ tarafta portlar yerleştirilir. Karaciğer ekartasyonu için sağ tarafta linea alba üzerinde ksifoid kemik ile umbilikus arasında uygun noktadan ayrıca $5 \mathrm{~mm}$ 'lik bir ekstra port yerleştirilir. Triangular ligaman kesilerek karaciğer mobilizw edilir. Çıkan kolon Gerota ile mezokolon arasına yapılan diseksiyonla mediale doğru mobilize edilir. Duodenum Kocher manevrası ile diseke edilmelidir. Sonrasında adrenal kitle peritonun arkasında gözlenir. Dördüncü porttan yerleştirilecek ekartör ile karaciğer kaldırılarak cerrahi alanda görüş arttırılır. Ekartör olarak yelpaze ekartör, fındık tampon veya grasper kullanılabilir (Resim $3 a-b)$. Periton karaciğer ile böbrek arasından başlanarak vena kava boyunca kaudale doğru insize edilir (Resim 4a). Ana adrenal venin vena kavaya girdiği bölge diseke edilir ve kliplenerek kesilir (Resim 4 b-c). Eğer adrenal ven tespit edilemezse kaudalde renal ven bulunur ve kraniale doğru diseksiyon yapilarak adrenal ven tespit edilir. Ana adrenal ven kliplendikten sonra adrenal bezin mediali, vena kava boyunca küçük venler kliplenerek diseke edilir. Sonrasında adrenal bez böbrek üst polünden ve karın arka duvarından serbestlenerek eksize edilir. Doğru planda diseksiyonda avaskuler alanda kanama daha az olurken diseksiyon sırasında aşırı kanama yanlış planı akla getirmelidir. Adrenal bez endobag'e konarak ikinci port deliğinin genişletilmesiyle çıartılır (Resim 4d) (Resim 5). Hastaya ihtiyaç halinde dren konulabilir.

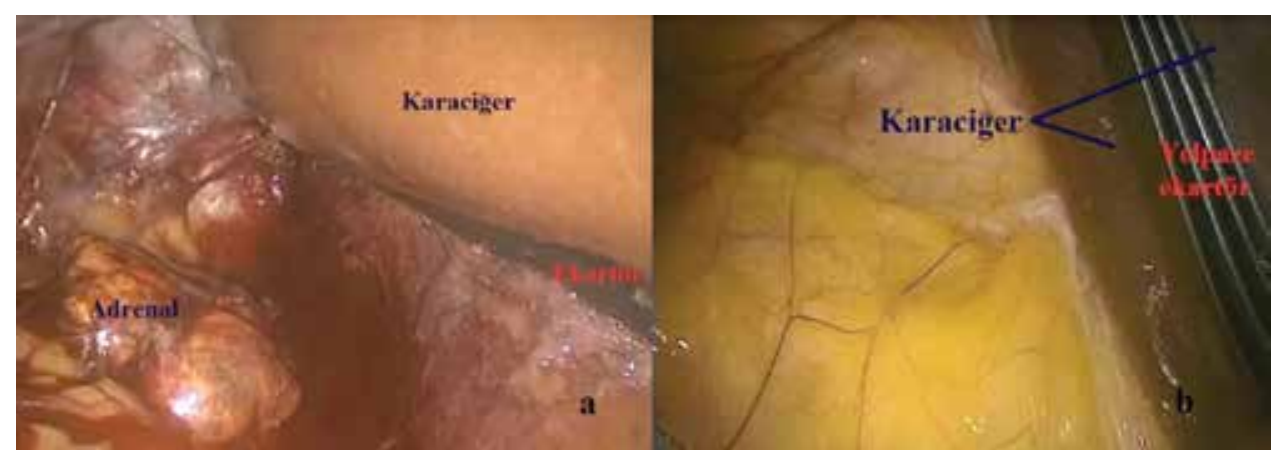

Resim 3: Laparoskopik sağ adrenalektomi a. Karaciğerin grasper ile ekartasyonu b. Karaciğerin yelpaze ekartör ile ekartasyonu

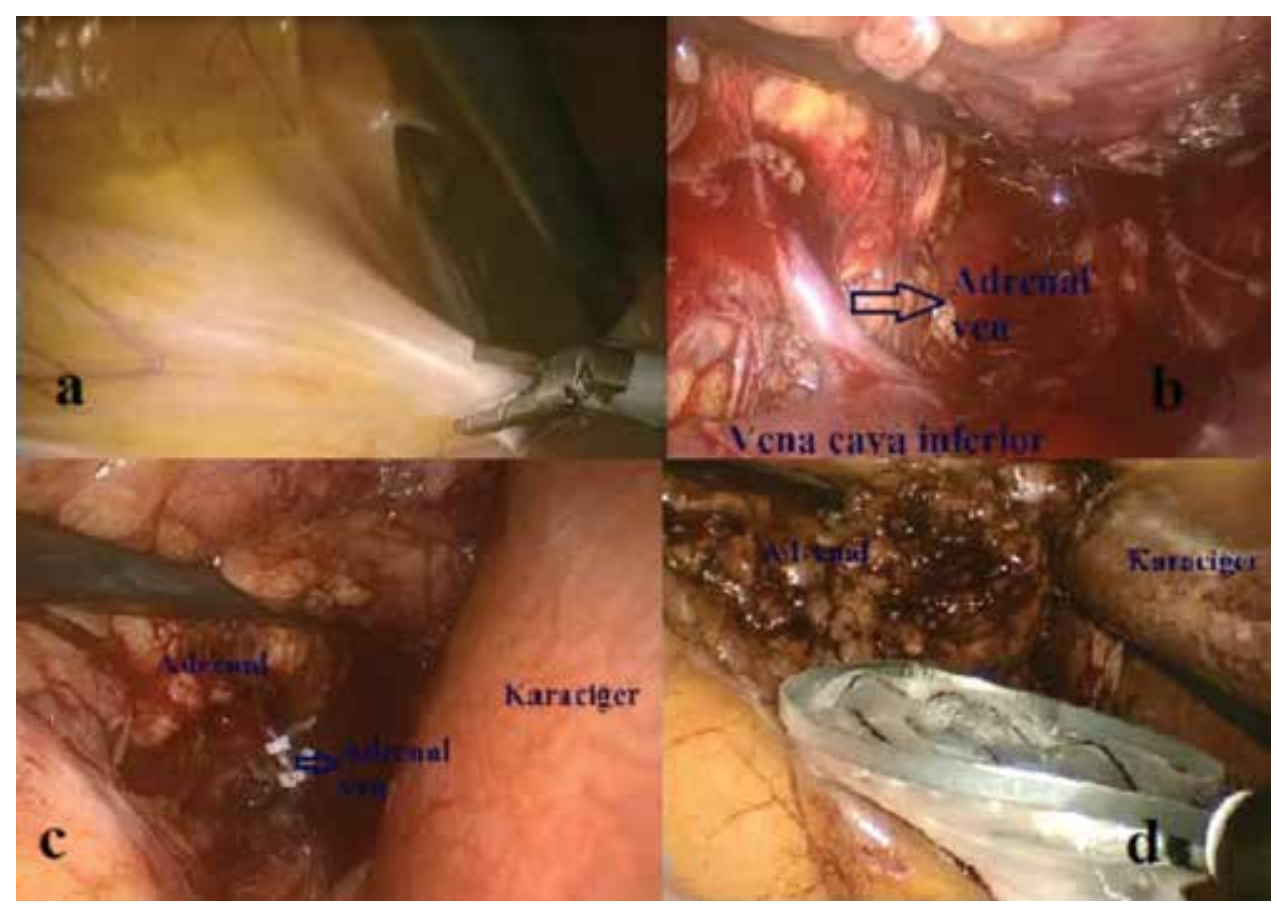

Resim 4: Laparoskopik sağ adrenalektomi a. Periton insizyonu b. Adrenal ven diseksiyonu c. Adrenal ven kliplenmesi d. Adrenal bezin endobag'e yerleştirilmesi 


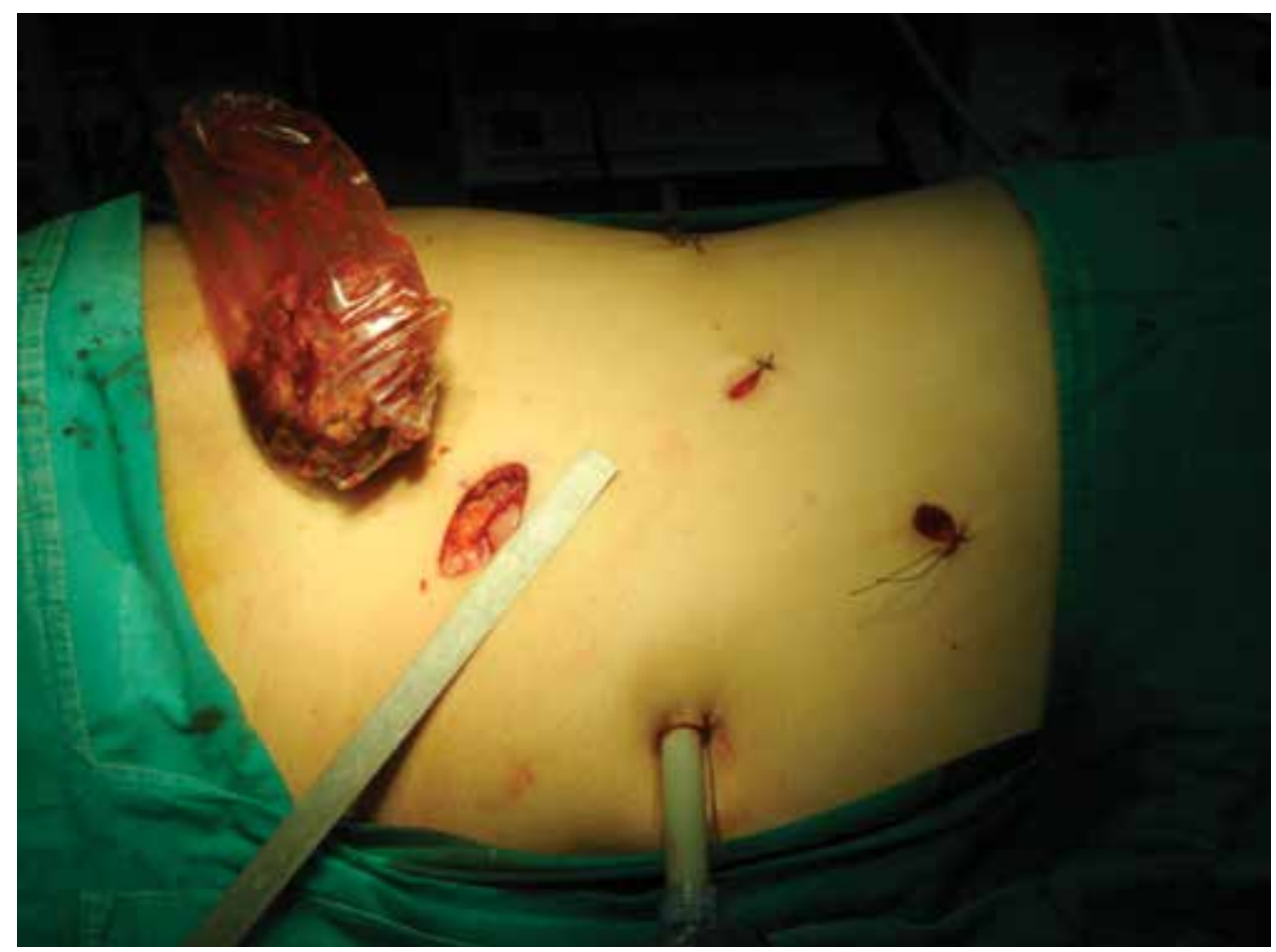

Resim 5: Sağ Transperitoneal laparoskopik adrenalektomi; vaka sonunda port kesi yerinden endobag içerisinde adrenal çıkarılması

\section{c. Tek port Laparoskopik Adrenalektomi}

Tek port laparoskopik adrenalektomi cerrahi prensip ve safhaları açısından tranperitoneoskopik adrenalektomi ile benzerdir, ancak port girişi ve kullanılan port ve fleksible malzemeler farklıdır. Port girişi için Hassan yöntemi prensibine uygun olarak umblikus seviyesinin $2 \mathrm{~cm}$ yukarısında $2 \mathrm{~cm}^{\prime}$ lik pararektal insizyon yapılır. Kas ayırıcı yöntemle peritona ulaşılır, periton insize edilerek port yerleştirilir (Resim 6 a-b). Port yerleştirmesi sonrasında adrenalektomi işlemi transperitoneal yaklaşımla aynı aşamalarda yapılır (Resim 7 a-d). Tek porttan tek insizyonla adrenalektomi operasyonu kozmetik açıdan daha avantajl olup operatif sonuçları laparaskopik cerrahiye benzerdir. Öğrenme eğrisi daha uzun ve daha fazla deneyim ve beceri gerektirmektedir. Yeni başlayanların öncelikle konvansiyonel yöntemde deneyim kazanması sonrası bu tekniğe geçmeleri olası komplikasyon ve olumsuz sonuçları önlenmesine yardımcı olacaktır.

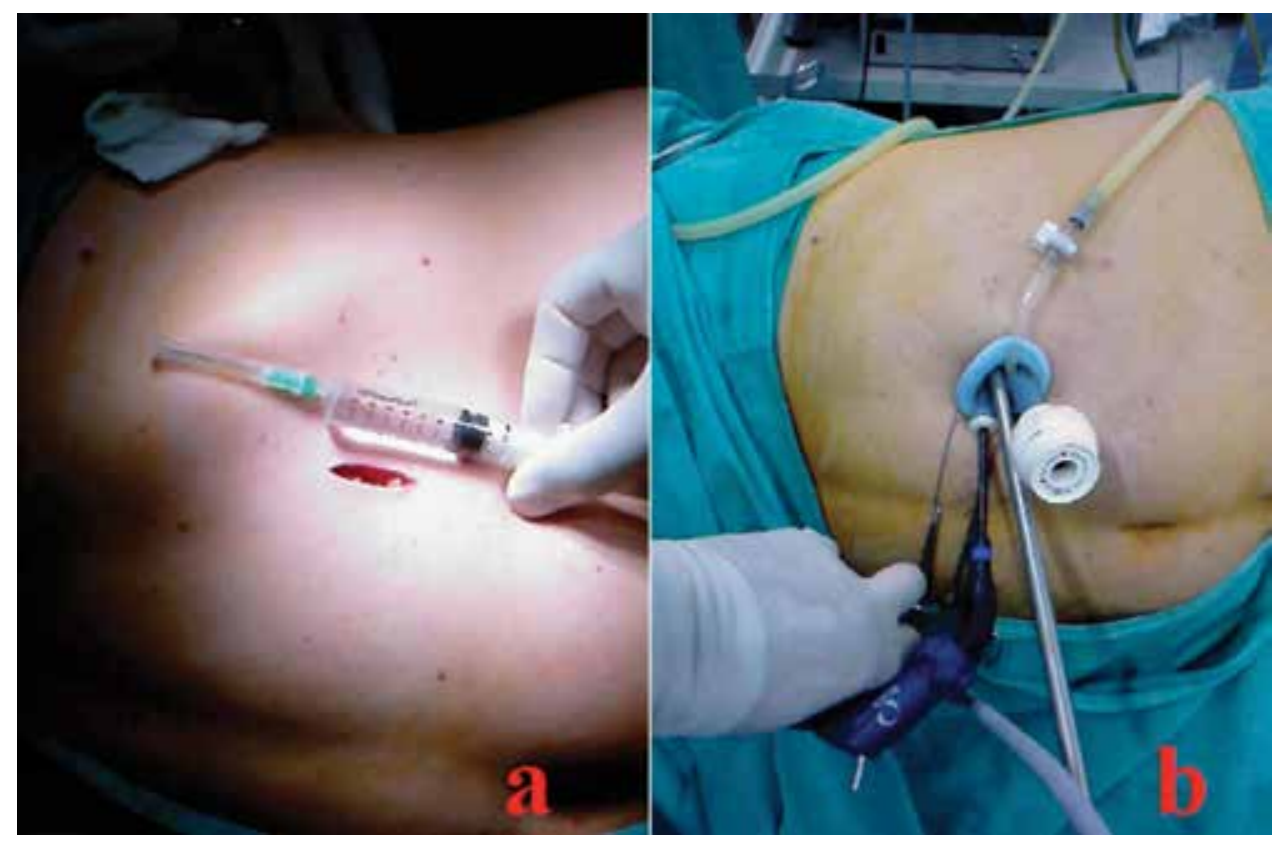

Resim 6: Tek port laparoskopik adrenalektomi a. İnsizyon b. Port üzerinde fleksible laparoskopik aletlerin kullanımı 


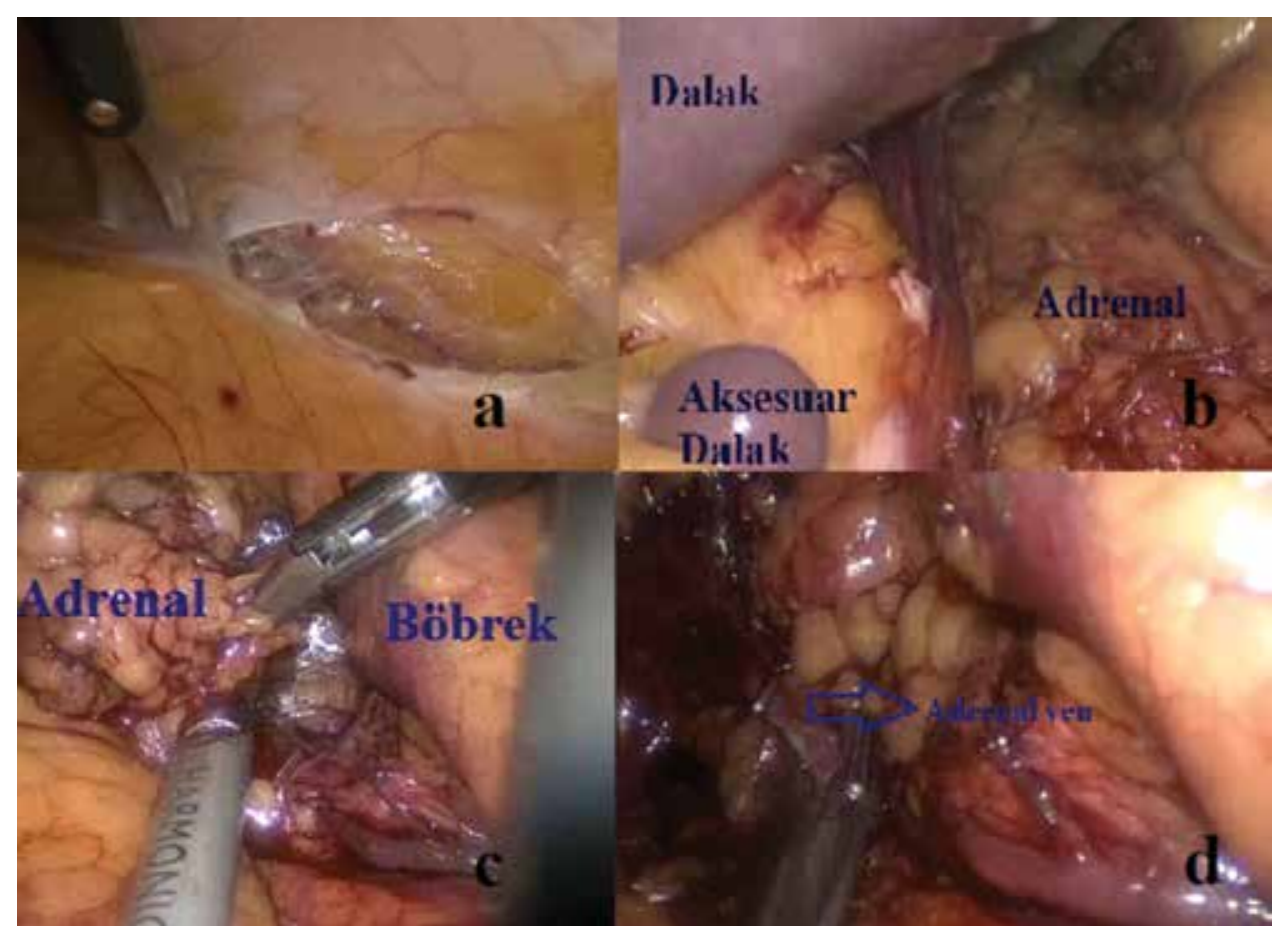

Resim 7: Tek port transperitoneal adrenalektomi aşamaları a. Todd hattı insizyonu b. Periton insizyonu sonrası adrenalin dalaktan diseksiyonu c. Adrenalin böbrek üst polünden diseksiyonu d. Adrenal venin diseksiyon sonrası kliplenmesi

\section{Retroperitoneal Laparoskopik Adrenektomi}

Hasta $90^{\circ}$ lateral dekubit pozisyonuna getirilir. Cerrahi öncesi hazırlıklar transperitoneal yaklaşımla aynıdır. Cerrah ve birinci asistan hastanın sırt tarafında, hemşire ve gerekirse ikinci asistan hastanın karın tarafında konumlanır.

Onikinci kotun kaudalinden $1.5 \mathrm{~cm}$ transvers insizyon sonrası keskin ve künt diseksiyonla retroperitona ulaşılır. Parmak yardımıyla balonun girebileceği boşluk oluşturulur, balon ile girilir. Takiben balon $600-800 \mathrm{ml}$ şişirilir sonrasında indirilip balon daha proksimale doğru yönlendirilerek tekrar şişirilir ve indilerek çıkartılır. Balonun çıktığı yere $10 \mathrm{~mm}$ port konur ve $\mathrm{CO} 2$ infüzyonu yapılır. Eğer gaz kaçağı varsa trokar çevresine sütür konabilir. 12. Kotun altında sakrospinal lateralinde birinci portun $4-5 \mathrm{~cm}$ posteriorunda olacak şekilde $10 \mathrm{~mm}$ olan ikinci port yerleştirilir. İlk portun $4-5 \mathrm{~cm}$ anterioruna ön aksiller hatta ilk iki portun hizasına denk gelecek şekilde $10 \mathrm{mmlik}$ üçüncü port yerleştirilir. İşlem sırasında gerekli olursa ekartasyon için dördüncü port yerleştirilebilir.

Retroperitoneal yaklaşımda $30^{\circ}$ optik kullanılır. Künt diseksiyonlarla diafram altı yağ dokusu serbestlenir ve böbrek üst polü mobilize edilir. Böylece adrenal bez görünür hale getirilir.

Sağ adrenal bez ve böbrek arka karın duvarından serbestlenir. Sonrasında vena kavaya doğru yapılan diseksiyonla adrenal vene ulaşılır. Bu esnada posteriordan çaprazlayan adrenal arter diseke edilip kliplenerek kesilir. Takiben adrenal bez çevre dokulardan diseksiyonla serbestlenerek, kald1rilır ve sonrasında vena kavadan çıktığı yerden adrenal ven tespit edilir. Adrenal ven diseksiyonla serbestlendikten sonra kliplenip kesilir.Kalan bölgeler diseke edilerek adrenal bez tümüyle serbestlenir.
Sol adrenal venin sol renal vene döküldüğ̈̈ yer, böbrek üst polün medialinde bulunur. Adrenal ven diseke edilerek serbestlenir ve kliplenerek kesilir. Kesilen adrenal ven takip edilerek bez diseksiyonla etraf dokulardan serbestlenir.

Adrenal bezin serbestlenmesini takiben adrenal bez spesmen torbasına konarak uygun port alanından çıkarılır. Gerekli durumlarda dren konabilir.

\section{Ameliyat Sonrası Bakım}

Fonksiyonel adrenal kitlesi olan hastalarda yakın hemodinamik ve elektrolit takibi gerekir. Feokromasitoma nedeniyle opere olan hastalar, hipotansiyondan korunmak için, hidrate edilmelidir. Cushing hastalı̆̆ı olan hastalarda başlanan kortizol endokrin bölümüyle işbirliği içinde aylar içinde azaltılarak kesilir. Konulan dren genellikle birinci gün çekilir. Genelde hastalar birinci veya ikinci gün hastaneden çıkabilir.

\section{Komplikasyonlar}

Laparoskopik adrenalektominin eğer cerrahi öncesi hazırlıkları doğru yapıldıysa ve cerrahi sırasında özenli davranıldıysa genelikle komplikasyon oranı düşüktür. Ancak her cerrahide olduğu gibi nadiren de olsa komplikasyon gelişebilir.

Ameliyat sırasında gelişen komplikasyonlar damar yaralanması ve cerrahi tarafına göre organ yaralanmaları ile ilgili olabilir. En sik peroperatif ve postoperatif komplikasyon kanamadır ancak \%5 hastada kan nakli ihtiyacı olur. İntraperitoneal organ yaralanmaları transperitoneal yaklaşımda daha sıktır. Sol tarafta dalak ve pankreas kuyruğu yaralanması, sağ tarafta ise karaciğer, safra kesesi, diafram, 
duodenum yaralanması, her iki tarafta barsak yaralanması açısından dikkatli olunmalıdır. Diafram yaralanması onarım veya toraks tüpü ile tedavi edilir. Sağ tarafta ayrıca vena cavada yaralanma riski vardır ve bu durumda acil laparotomi gerekli olacağı unutulmamalıdır. Postoperatif komplikasyonlar kanama, yara yeri enfeksiyonu, hematom, tromboembolik olayı içerir (13). Ayrıca Cushing sendromlularda nadiren nekrotizan pankreatit gelişebilir (13).

\section{Sonuç}

Laparoskopik adrenalektomi minimal invaziv yaklaşımla daha iyi kozmetik sonuç, daha az morbidite, daha az hastanede kalış, daha erken günlük hayata başlangıçla tercih edilen bir yöntemdir.

\section{Kaynaklar}

1. Gagner M, Lacroix A, Bolté E.Laparoscopic adrenalectomy in Cushing's syndrome and pheochromocytoma. N Engl J Med. 1992 Oct 1;327(14):1033

2. Brunt LM, Doherty GM, Norton JA, Soper NJ, Quasebarth MA, Moley JF. Laparoscopic adrenalectomy compared to open adrenalectomy for benign adrenal neoplasms. J Am Coll Surg. 1996 Jul;183(1):1-10.

3. Thompson GB, Grant CS, van Heerden JA, Schlinkert RT, Young WF Jr, Farley DR, Ilstrup DM.

4. Laparoscopic versus open posterior adrenalectomy: a case-control study of 100 patients. Surgery. 1997 Dec;122(6):1132-6.

5. Constantinides VA, Christakis I, Touska P, Palazzo FF Systematic review and meta-analysis of retroperitoneoscopic versus laparoscopic adrenalectomy. Br J Surg. 2012 Dec;99(12):1639-48.Review.

6. Guerrieri M, Campagnacci R, De Sanctis A, Baldarelli M, Coletta M, Perretta S. The learning curve in laparoscopic adrenalectomy. J Endocrinol Invest. 2008 Jun;31(6):531-6.

7. Lal G, Duh QY. Laparoscopic adrenalectomy--indications and technique. Surg Oncol. 2003 Aug;12(2):105-23.

8. Korivi BR, Elsayes KM.Cross-sectional imaging work-up of adrenal masses.World J Radiol. 2013 Mar 28;5(3):88-97.
9. Cooper AB, Habra MA, Grubbs EG, Bednarski BK, Ying AK, Perrier ND, Lee JE, Aloia TA. Does laparoscopic adrenalectomy jeopardize oncologic outcomes for patients with adrenocortical carcinoma? Surg Endosc. 2013 Nov;27(11):4026-32.

10. Miller BS, Ammori JB, Gauger PG, Broome JT, Hammer GD, Doherty GM.Laparoscopic resection is inappropriate in patients with known or suspected adrenocortical carcinoma. World J Surg. 2010 Jun;34(6):1380-5.

11. Jurowich C, Fassnacht M, Kroiss M, Deutschbein T, Germer CT, Reibetanz J.Horm Metab Res. 2013 Feb;45(2):130-6. doi: 10.1055/s-0032-1331743. Epub 2013 Jan 11.Is there a role for laparoscopic adrenalectomy in patients with suspected adrenocortical carcinoma? A critical appraisal of the literature.

12. Brix D, Allolio B, Fenske W, Agha A, Dralle H, Jurowich C, Langer P, Mussack T, Nies C, Riedmiller H, Spahn M, Weismann D, Hahner S, Fassnacht M; German Adrenocortical Carcinoma Registry Group. Laparoscopic versus open adrenalectomy for adrenocortical carcinoma: surgical and oncologic outcome in 152 patients. Eur Urol. 2010 Oct;58(4):609-15.

13. Brix D, Allolio B, Fenske W, Agha A, Dralle H, Jurowich C, Langer P, Mussack T, Nies C, Riedmiller H, Spahn M, Weismann D, Hahner S, Fassnacht M; German Adrenocortical Carcinoma Registry Group.

14. Fosså A, Røsok BI, Kazaryan AM, Holte HJ, Brennhovd B, Westerheim O, Marangos IP, Edwin B. Laparoscopic versus open surgery in stage I-III adrenocortical carcinoma -- a retrospective comparison of 32 patients. Acta Oncol. 2013 Nov;52(8):1771-7.

15. Gumbs AA, Gagner M.Laparoscopic adrenalectomy. Best Pract Res Clin Endocrinol Metab. 2006 Sep;20(3):483-99.

Yazışma Adresi:

Ismet Yavaşcaoğlu

Uludă̆ Üniversitesi, Tıp Fakültesi,

Üroloji Anabilim Dalı, Bursa

Tel: +90 5323542344

e-mail: ismetyavascaoglu@gmail.com 